\title{
Paul Ricoeur e um novo conceito de interpretação: da hermenêutica dos símbolos à hermenêutica do discurso
}

\author{
Paul Ricoeur and a new concept of interpretation: \\ from the hermeneutics of symbols to the hermeneutics of discourse
}

Manuel Tavares ${ }^{1}$

\begin{abstract}
Resumo: Este texto é uma reflexão sobre a riqueza da problemática hermenêutica como estruturante do pensamento de Ricoeur, seguindo o próprio percurso do autor e esclarecendo a transição de uma hermenêutica dos símbolos para uma hermenêutica do discurso, não esquecendo que o projeto do filósofo e os horizontes do seu pensamento são a construção de uma nova antropologia e de uma ontologia da compreensão do ser humano aplicáveis à problemática educacional. Esclareceremos o que se entende por hermenêutica da via longa que passa, necessariamente, por opções metodológicas, em oposição à via curta ou imediata defendida por Husserl e Heidegger; das nossas reflexões emerge a questão do mal por intermédio de uma abordagem da hermenêutica dos símbolos e dos mitos. Finalmente, a hermenêutica do discurso como produção de sentidos ocupará a última parte deste texto. O mundo humano é constituído por todas as referências abertas pelos textos, sejam poéticos, míticos ou de outra índole. A ontologia proposta por Ricoeur, ontologia quebrada, ganha maior densidade por intermédio do percurso transitório entre a hermenêutica simbólica e a hermenêutica do discurso restauradora do sentido.
\end{abstract}

Palavras-chave: Paul Ricoeur; hermenêutica; hermenêutica dos símbolos; hermenêutica do discurso; mal.

\begin{abstract}
This text is a reflection on the richness of the hermeneutical problematic as structuring of Ricoeur's thought, following the author's own course and clarifying the transition from a hermeneutic of the symbols to a hermeneutic of the discourse, not forgetting that the philosopher's project and the horizons of the his thinking is the construction of a new anthropology and an ontology of the understanding of the human being, applicable to educational problematic. We shall clarify what is meant by the hermeneutics of the long way, as opposed to the short or immediate path advocated by Husserl and Heidegger; the question of evil emerges from our reflections through an approach to the hermeneutics of symbols and myths. Finally, the hermeneutics of discourse as production of meanings will occupy the latter part of this text. The human world is made up of all the references open to texts, be they poetic, mythical or otherwise. The ontology proposed by Ricoeur, a broken ontology, gains greater density through the transitory course between symbolic hermeneutics and the hermeneutics of the restorative discourse of meaning. The plurality of meanings that the narratives enable represents a greater breadth for the understanding of the human being in the world and for a reflection on the truth.
\end{abstract}

Keywords: Paul Ricoeur; hermeneutics; hermeneutics of symbols; hermeneutics of discourse; evil.

\footnotetext{
${ }^{1}$ Doutorado em Filosofia pela Universidade de Sevilha (SP). Professor do Programa de Pós-Graduação em Educação (PPGE) da Universidade Nove de Julho (UNINOVE), São Paulo/SP < manuel.tavares@outlook.com.br>
} 


\section{Introdução}

Paul Ricoeur é, inegavelmente, um dos maiores pensadores do pós Segunda Guerra Mundial e, seguramente, um dos mais importantes representantes da hermenêutica contemporânea. O objeto de reflexão do presente texto centra-se na hermenêutica, como teoria da interpretação e, sobretudo, na transição de uma hermenêutica dos símbolos para uma hermenêutica do discurso. Consideramos que esta transição constitui uma ampliação do processo metodológico do autor e uma confirmação da sua via longa, em oposição à via curta levada a cabo pela fenomenologia husserliana e heideggeriana.

O seu percurso filosófico está indissoluvelmente ligado à metodologia que se inicia por uma filosofia reflexiva, por influência de Nabert, se concentra na fenomenologia, por influência de Husserl, para, numa perspectiva eidética, pensar as estruturas fundamentais da vontade humana e estabelecer as relações entre voluntário e involuntário. Posteriormente, amplia as reflexões para uma empírica da vontade. A conciliação ontológica entre o voluntário e o involuntário revela a reconquista da experiência do cogito em toda a sua amplitude, ou seja, implica a integração, no plano da subjetividade, das necessidades, de todo o involuntário corporal e de todos os motivos, incluindo os inconscientes, que estão sempre na base da ação humana. A hermenêutica constitui, assim, o percurso metodológico que permite compreender o ser humano, a sua existência e as relações com o mundo.

Tomamos o conceito de hermenêutica, não como mero processo metodológico de interpretação visando a compreensão, mas como uma verdadeira filosofia da praxis que contesta todas as formas de pensamento meramente utilitárias visando a eficácia. A possibilidade de escolha e decisão por parte do ser humano, a sua imputabilidade perante os atos que pratica e as suas relações de reciprocidade ou não com os outros, eis as grandes linhas estruturantes de uma filosofia da praxis que pressupõe, do nosso ponto de vista, a reabilitação das grandes narrativas, dos símbolos e dos mitos que fomentam a coesão social e política em que radica a responsabilidade e solidariedade da vida em conjunto. (OMITIDO, 2016). A racionalidade hermenêutica reassume-se como sabedoria prática que não só interpreta a linguagem, os símbolos, os discursos e os textos, mas recria em ato a pluralidade de sentidos. É na simbólica do mal que Ricoeur 
inicia a sua hermenêutica, como filosofia da praxis ética e política do ser humano. Esta filosofia exige uma via longa de reflexões sobre a semântica da ação, que culminarão em Temps et Récit.

Pretendemos, neste texto, refletir sobre a riqueza da problemática hermenêutica como estruturante do pensamento de Ricoeur, seguindo o próprio percurso do autor e esclarecendo a transição de uma hermenêutica dos símbolos para uma hermenêutica do discurso, não esquecendo que o projeto do filósofo e os horizontes do seu pensamento são a construção de uma nova antropologia e de uma ontologia da compreensão do ser humano, imprescindíveis para pensar a educação numa perspectiva libertadora e emancipatória. Esclareceremos, em primeiro lugar, o que se entende por hermenêutica da via longa, em oposição à via curta ou imediata defendida por Husserl e Heidegger; incontornavelmente, emerge das nossas reflexões a questão do mal por intermédio de uma abordagem da hermenêutica dos símbolos e dos mitos. Finalmente, a hermenêutica do discurso como produção de sentidos ocupará a última parte deste texto.

\section{Hermenêutica da via longa}

O percurso da «via longa» implica uma ampliação metodológica que passa, necessariamente, pela hermenêutica. Numa primeira fase, a hermenêutica reduz-se à descoberta da estrutura comum a todo o símbolo para, progressivamente, se abrir ao conflito de interpretações rivais. Com efeito, aparece sempre, como cenário, uma ontologia da compreensão do ser humano, da sua presença na vida e na história e das suas múltiplas relações com os outros, tanto no presente como no passado histórico, configurado por uma diversidade de representações, de discursos significantes e dos símbolos das culturas humanas. O que Ricoeur pretende, mais do que arbitrar um conflito de interpretações rivais, é a superação desse conflito por intermédio da substituição de uma hermenêutica redutora por uma hermenêutica restauradora do sentido. O conceito de símbolo perde o seu sentido estático, entendido como possuidor de um único sentido, para passar a ser algo susceptível de interpretação, ganhando, assim, uma perspectiva mais ampla, enquanto refiguração textual e narrativa da experiência humana, da ação e do mundo.

O discurso é um acontecimento da linguagem, um complexo de símbolos que escondem, dentro de si, mistérios que precisam de ser 
desvelados. Essa é a função da hermenêutica: desvelando e revelando os sentidos do mundo humano presentes, muitas vezes, de um modo latente, na linguagem, no discurso e nos símbolos que os constituem, considerando que os símbolos são expressões de duplo sentido e que manifestam as múltiplas relações do ser humano consigo próprio, com os outros e com o mundo.

Se tivermos em consideração a evolução do projeto filosófico de Ricoeur, verificamos que tal evolução também afeta, de um modo fundamental, a sua metodologia. Assim, encontramos duas concepções de hermenêutica: a primeira, como interpretação dos símbolos; a segunda, como interpretação dos textos escritos.

No que diz respeito à primeira concepção, é necessário distinguir duas fases: na primeira, o objeto da hermenêutica é a interpretação do simbolismo religioso, procurando assumir o sentido de tal simbolismo no âmbito da reflexão filosófica; tal hermenêutica mantém os símbolos e os mitos enquanto símbolos e mitos, pensando a partir deles. A interpretação será um trabalho reflexivo que saiba desenvolver os níveis de significação implícitos em toda a significação literal. A segunda fase é constituída pelo conflito de interpretações. Este conflito emerge quando, por influência de Freud, Ricoeur tem que modificar o seu conceito de símbolo.

A segunda concepção de hermenêutica é definida, fundamentalmente, como interpretação do texto escrito. Neste caso, um texto é, explicita Ricoeur, «todo o discurso fixado pela escrita. Segundo esta definição, a fixação pela escrita é constitutiva do próprio texto» (RICOUER, 1986, p. 154), o que quer dizer que a palavra, pronunciada física ou mentalmente, é sempre anterior ao texto.

$\mathrm{Na}$ etapa do conflito de interpretações, a filosofia reflexiva de Ricoeur converte-se numa espécie de meta-hermenêutica, dado que a finalidade consiste em arbitrar esse conflito. O que se pretende é, afinal, mais do que arbitrar o conflito de interpretações, superar esse conflito por meio da substituição de uma hermenêutica redutora por uma hermenêutica restauradora do sentido.

O problema hermenêutico já se tinha constituído na exegese bíblica ${ }^{2}$ e é nesta tradição que Ricoeur encontra as bases da sua hermenêutica,

\footnotetext{
${ }^{2} \mathrm{O}$ texto sagrado é o lugar onde se diz o sagrado. Esse dizer é indireto e é decifrável por intermédio do duplo sentido de um texto que nos comunica uma certa condição ontológica. O duplo sentido do texto bíblico apela a uma
} 
ainda que considere que a exegese bíblica representa uma concepção restrita da hermenêutica. Ela constitui uma hermenêutica regional em relação à filosófica que, por sua vez, se afirma como hermenêutica geral. (RICOEUR, 1986). Não obstante, foi no âmbito da exegese que se desenvolveram as noções de analogia, alegoria e dos vários sentidos, como o simbólico, o histórico, o espiritual e o literal; foi também a partir dela que a noção de texto se ampliou, por analogia, a outros domínios. Deste modo, na Idade Média, começou a falar-se de interpretação da natureza e, a partir do Renascimento, é a própria interpretação da natureza que se converte em modelo inspirador para a interpretação da Sagrada Escritura.

Todavia, não se pode menosprezar o fato de que, com o aparecimento da psicanálise freudiana, não é só a escrita que está sujeita à interpretação, mas também os sonhos, os rituais, as obras de arte e todos os signos que possam ser considerados como um texto; mas é com Nietzsche que toda a filosofia se converte em teoria da interpretação, em suspeita em relação a todas as ilusões e todas as máscaras de uma consciência imediata de si mesmo. A hermenêutica da suspeita aspira a formular uma noção de consciência que, depois de enfrentar as suas ilusões, torne possível uma ontologia do sujeito, ainda que sempre parcial. (MACEIRAS, 1987).

A reflexão é, assim, sempre um trabalho de interpretação. Daí que a filosofia reflexiva seja, necessariamente, hermenêutica. Neste sentido, a filosofia de Ricoeur introduz uma importante viragem relativamente às suas posições fenomenológicas anteriormente assumidas.

Se é verdade que o exercício de reflexão é uma tentativa de reapropriação do nosso ser, se é «um esforço por existir» (RICOEUR, 1969, p. 21), esta reapropriação implica a interpretação de todo o legado cultural, sobretudo dos símbolos históricos que são, afinal, manifestações da presença do ser humano no mundo.

Consequentemente, é pelo facto de eu não estar imediatamente na posse de mim mesmo, porque a reflexão não é intuição de si por si, que é necessário a apropriação do que eu sou decifrando as múltiplas expressões do meu esforço por existir. É através dos signos públicos e privados da minha actividade no mundo, é através da obra, a cultura, a instituição 
política e a história que poderei apropriar-me da minha afirmação originária. (GISEL, 1970, p. 177).

Efetivamente, é na simbolização que atua o desejo de ser e se exprime o poder de produção e invenção que abre ao homem o espaço e o horizonte do possível. É na simbolização, afinal, que atua o poder míticopoético da imaginação humana como força produtiva e, simultaneamente, a capacidade projetiva que define, até certo ponto, a liberdade humana.

Como afirmámos, a função da hermenêutica limita-se, numa primeira fase, à interpretação dos símbolos tomados como «signos de duplo sentido.» (RICOEUR, 1969, p. 17). De fato, o símbolo remete para algo mais além de si mesmo e, por isso, implica múltiplas interpretações, o que significa que «a polissemia é um fenómeno central para a hermenêutica.» (RICOEUR, 1987, p. 143). No entanto, apresentam-se algumas dificuldades à investigação específica das representações simbólicas.

Em primeiro lugar, são múltiplos os ramos da investigação que procuram clarificar o sentido subjacente ao conceito de representação simbólica. Por exemplo, a perspectiva psicanalítica considera que uma representação simbólica é um sintoma de um conflito psíquico inconsciente, o que se distingue, claramente, da análise poética da expressão simbólica que privilegia a força da imaginação criativa. Em segundo lugar, o símbolo é uma expressão linguística, é uma realidade sintática e semântica mas que ultrapassa largamente os contornos da linguagem. De fato, a sua estrutura de sentido indica sempre a existência de uma tensão entre dois sentidos e duas interpretações, antes de ser uma tensão entre o sentido e a realidade. O símbolo pode ser designado como «o sentido do sentido», uma vez que, de acordo com a perspectiva de Ricoeur, que tem por fundamento a concepção de «função simbólica» ${ }^{3}$ de Cassirer. O sentido aponta sempre para uma realidade extra-linguística e implica sempre uma tensão entre duas significações.

\footnotetext{
${ }^{3}$ A posição de Ricoeur, em relação ao conceito de «forma simbólica», proposto por Cassirer, não é sempre a mesma. Na sua obra sobre Freud, critica a aplicação demasiado geral da noção de Cassirer: «uma definição demasiado ampla é que faz com que a «função simbólica» tenha uma função geral de mediação por meio da qual o espírito, a consciência, constrói os seus universos perceptivos e discursivos; como se sabe, esta definição é a de Cassirer na sua Philosophie des formes symboliques.» (RICOEUR, 1995, p. 19). No entanto, em Temps et récit I (1991), pode apreciarse uma clara aproximação à noção de «função simbólica»: «entre uma acepção demasiado pobre e uma acepção demasiado rica, optei por um uso próximo ao de Cassirer em Philosophie des formes symboliques na medida em que, para ele, as formas simbólicas são processos culturais que articulam a totalidade da experiência.» p. 91.
} 


\section{Hermenêutica dos símbolos e dos mitos: em torno do problema do mal}

Considerando que o ser humano é um animal simbólico, o mito surge, em primeiro lugar, como uma representação simbólica que é anterior ao pensamento filosófico e que, no seu simbolismo, revela a participação ontológica do ser humano, a sua relação com o cosmos e com o sagrado e, simultaneamente, o modo como o sujeito se realiza no mundo. Consequentemente, a filosofia não pode esquecer o carácter universal e participante do mito e do símbolo quando pretende refletir sobre a experiência integral do ser humano. A reflexão sobre a simbólica surge, de fato, num determinado momento da reflexão filosófica, sobretudo porque a cultura moderna tem a tendência a valorizar todos os discursos que exprimem a realidade em termos unívocos, esquecendo que a realidade se diz de diferentes maneiras, não se devendo privilegiar uma delas em detrimento de outras.

O ponto de partida de Ricoeur não é a especulação, uma vez que esta não permite captar diretamente a experiência espontânea das vivências humanas. Começa, então, pelos símbolos primários e pelos mitos; os mitos são narrativas tradicionais que remetem para os tempos primordiais e contam-nos como tudo começou a ser, desde o cosmos até à ação e ao pensamento humanos. O mito, enquanto mito, é uma narrativa e não propriamente uma explicação mas, enquanto relato, revela uma potencialidade exploratória e compreensiva. Através dele pode-se compreender a totalidade da realidade humana e a sua relação indissolúvel com o cosmos e com a transcendência. Mas, por outro lado, o mito e a sua linguagem simbólica, tendo em conta o seu carácter emotivo e fantástico, não podem inserir-se diretamente no discurso filosófico, o que implica a necessidade de uma 'desmitologização' do mito - no sentido de uma mera captação racional e explicativa - entendendo-o, então, a partir do símbolo, dos símbolos primários. A interpretação hermenêutica não pode penetrar na a-historicidade do tempo mítico e na consciência cultural da época primitiva. É, pois, pela via da desmitologização que se pode contactar com a função simbólica do mito, com a sua verdadeira e profunda realidade:

O filósofo deve apostar, deve perguntar pela verdade como crença. Deve penetrar no "círculo hermenêutico de 'compreender para crer e crer para compreender" Esta "verdade do hermeneuta” significa, antes de mais, não o regresso à ingenuidade originária, à percepção imediata da consciência 
em que as culturas viviam na época primitiva referidas directamente aos seus mitos. Este sentido, vive uma época de desmitologização em que o mito já não pretende ligar-se explicativamente à história, põe-nos em contacto com a verdadeira realidade do mito, com a sua função simbólica essencial. (PRIETO, 1980, p. 394).

Ricoeur vê nos símbolos e nas metáforas da linguagem um caminho para a aquisição de uma consciência mais concreta da situação ontológica do ser humano. A compreensão humana será mais completa por intermédio da ligação entre o ser da humanidade e o ser de todos os entes, seguindo a indicação do pensamento simbólico. Tendo em conta a amplitude e a variedade das zonas de emergência do símbolo, este último representa, de fato, uma ampla abertura à reflexão filosófica.

Todo o símbolo implica as dimensões cósmica, onírica e poética e o aspecto reflexivo dos símbolos não se compreende a não ser pela sua relação com estas três funções do símbolo. Estes três domínios constituem as três «zonas de emergência do simbólico.» (RICOEUR, 1988, p. 174). É a linguagem que unifica os três domínios simbólicos referidos, uma vez que todos se manifestam pela palavra. Mais ainda: todos eles têm um carácter polissémico, uma estrutura de duplo sentido; deste modo, pode dizer-se que há uma estrutura comum aos três tipos de símbolos e que tal estrutura constitui a sua essência.

O ser humano começa por intuir as dimensões do sagrado na natureza; a construção da linguagem simbólica faz-se sobre estas hierofanias originárias. Efetivamente, os primeiros símbolos referem-se a elementos cósmicos e é neste fundo cósmico que reside a riqueza essencial do símbolo. Os primeiros símbolos são, de facto, realidades cósmicas (sol, lua, água) que se manifestam pela palavra. Por isso mesmo e antes de tudo, como diz Ricoeur, «o símbolo antes de dar que pensar, dá que falar.» (RICOEUR, 1988, p. 174). O símbolo como palavra, como signo, é a condensação da realidade cósmica na medida em que todo o símbolo se constitui a partir de uma significação de primeiro grau ligada à experiência da natureza. Assim, a primeira zona de emergência é constituída pelo simbolismo cósmico e é objeto da fenomenologia da religião. ${ }^{4}$ Ricoeur parte das concepções de Mircea

\footnotetext{
${ }^{4}$ Recorde-se que, para a fenomenologia da religião, o símbolo é a expressão concreta da transcendência do real. Deste modo, a realidade é sempre uma hierofania, isto é, manifestação do sagrado. Cf. P. Ricoeur (1975) «Parole et symbole», Revue des sciences religieuses, 49, $\mathrm{n}^{\circ}$ 1-2, p. 152. Veja-se, também, M. Eliade (s/d) O sagrado e o profano. A essência das religiões. Lisboa: Edições Livros do Brasil, p. 25.
} 
Eliade, ainda que aluda também a Van der Leeuw e M. Leenhard. Pode dizerse que a noção de símbolo apresentada por Ricoeur é inspirada nestes três autores. Com efeito, na concepção de hierofania e de símbolo de Mircea Eliade aparece já o carácter polissémico da noção de símbolo. A natureza, diz Eliade, «nunca é exclusivamente "natural": está sempre carregada de um valor religioso.» (ELIADE, s/d, p. 25. Nesta perspectiva, uma realidade cósmica incorpora outra coisa que é distinta de si mesma e adquire realidade na medida em que é sacralizada. Os símbolos são, para Eliade, signos de realidades transcendentes e não possuem valor em si mesmos, isolados do todo, mas adquirem valor enquanto integrados num sistema cósmico. Todavia, para Ricoeur, o que é importante numa primeira reflexão é que todo o símbolo tem um duplo sentido e que a expressividade cósmica se diz na linguagem. Além disso, é pela linguagem que se realiza a aproximação entre o simbolismo e a reflexão filosófica.

A segunda zona de emergência do símbolo é constituída pelo âmbito do onírico. A análise e exploração deste simbolismo é da competência da psicanálise. Ricoeur considera que «é no sonho que se pode surpreender a passagem da função 'cósmica' para a função 'psíquica' dos simbolismos mais fundamentais e mais estáveis da humanidade.» (RICOEUR, 1988, 176). No entanto, o ser humano, ao manifestar no cosmos a dimensão do sagrado, interioriza-a em si mesmo ou, o que é a mesma coisa, a manifestação do sagrado nas coisas é o resultado de uma consciência religiosa. Neste sentido, não há que separar os símbolos cósmicos dos símbolos oníricos. De facto, as produções oníricas a nível individual não são mais do que a repetição das representações de uma determinada cultura. O inconsciente individual é o reflexo - utilizando a terminologia de Jung - de um inconsciente coletivo. Além disso, pode-se ainda dizer que o ser humano é um microcosmos; deste ponto de vista, o ser humano realiza, numa pequena escala, tudo o que acontece no macrocosmos.

Do mesmo modo que os símbolos cósmicos, também a simbologia onírica pode expressar-se por uma linguagem. O sonho é uma narrativa que deve ser interpretada. Assim sendo, como dizíamos, a estrutura do simbolismo cósmico é a mesma do simbolismo onírico. No entanto, como veremos, a noção de símbolo é reformulada por Ricoeur na obra De l'interprétation. Essai sur Freud. De facto, a noção de símbolo apresentada em La symbolique du mal é demasiado restrita, dado que o símbolo é definido por analogia entre o sentido literal e o sentido oculto. O objetivo de La 
symbolique du mal é a descoberta da estrutura comum a todo o símbolo; em De l'interprétation. Essai sur Freud, o símbolo surge, então, como uma estrutura de duplo sentido susceptível de múltiplas interpretações.

A expressão ‘duplo sentido’ parece designar a distinção primordial entre as duas vertentes da experiência do sentido: de um lado, o sentido dá-nos conta da experiência transcendental da função simbólica enquanto condição de possibilidade de um qualquer ato concreto de significação mas, por outro lado, exprime o movimento que constitui a nossa experiência imediata. Neste sentido, uma narrativa ou mesmo uma metáfora são expressões simbólicas de duplo sentido, não tanto pelo facto de serem linguagens figuradas, mas porque realizam, em simultâneo, o duplo movimento de presença e ausência. Assim, o conceito de símbolo perde o seu carácter estático, entendido como sentido unívoco, passando a ser algo susceptível de interpretação e ganhando uma perspectiva mais ampla, enquanto refiguração textual e narrativa da experiência humana, da ação e do mundo. Nesta perspectiva, a hermenêutica deixa de ter um âmbito restrito à exegese para passar a ser uma investigação filosófica e narrativa sobre o ato de constituição do sentido.

A terceira zona de emergência do símbolo é constituída pela imaginação poética. A imagem poética é, sobretudo, palavra e não tanto imagem da realidade. Nesta perspectiva, a imaginação poética aproximanos do ser que fala, da sua experiência e das suas vivências, «mostra-nos a expressividade no estado nascente.» (RICOEUR, 1988, p. 177).

Do mesmo modo que nos símbolos anteriores, que possuem a mesma estrutura, a estrutura da imagem poética é a mesma que a do sonho. Esclareçamos a questão: o que faz com que a poesia seja um discurso sedutor e fascinante é o facto de todo o discurso poético ser simbólico e metafórico; quer dizer, o que se diz oculta um sentido que não é o literal, o patente, mas outro que se oculta sob o primeiro sentido; o referente do primeiro não é exatamente o referente do segundo.

Em La symbolique du mal Ricoeur capta o essencial do símbolo por meio de uma aproximação descritiva. Por outro lado, a análise teórica pretende distinguir entre o que é símbolo e o que não é por intermédio de uma criteriologia dos símbolos.

Em primeiro lugar, «os símbolos são signos (...): são expressões que comunicam um sentido» (RICOEUR, 1988, p. 177) por meio da 
palavra. Sendo assim, os símbolos possuem um sentido, uma intencionalidade de significar alguma coisa.

Em segundo lugar, se há pontos comuns entre o símbolo e o signo, há também diferenças, dado que nem todo o signo é símbolo; no signo existe uma referência a algo, mas os símbolos têm uma dupla intencionalidade: uma primeira, literal, que é comum a qualquer signo convencional e, mais concretamente, linguístico; e uma segunda intencionalidade, um sentido analógico, que faz do símbolo algo sempre relativamente opaco. Mas há que insistir no facto de que, em ambos os casos, a linguagem é a mediação entre as vivências humanas e a sua expressão. Sem a linguagem a experiência permaneceria silenciosa e obscura.

A terceira aproximação a uma descrição do símbolo tem a ver com a compreensão da relação analógica entre o sentido literal e o sentido simbólico. Efetivamente, não se trata de uma mera analogia entre o sentido literal e o sentido latente; no símbolo, o primeiro sentido aponta sempre para além de si mesmo, para um sentido simbólico que, por sua vez, só se constitui no e pelo primeiro sentido ou literal; «o símbolo é o movimento do primeiro sentido que nos faz participar no sentido latente.» (RICOEUR, 1995, p. 178).

Seguidamente, Ricoeur distingue símbolo e alegoria. A distinção entre ambos está na relação que mantêm com a hermenêutica. O símbolo é anterior a toda a interpretação, enquanto que a alegoria é já em si mesma uma espécie de interpretação. O símbolo dá o seu sentido «na transparência do enigma», enquanto a alegoria «é interpretação por tradução.» (RICOEUR, 1995, p. 179). Por este motivo, Ricoeur considera que é mais correto falar de interpretação alegorizante, uma vez que a alegoria é mais uma modalidade da hermenêutica do que uma interpretação espontânea de signos. Por outro lado, o símbolo, susceptível de uma interpretação, não se relaciona com a acepção lógica do símbolo. A descrição eidética, proposta na criteriologia do símbolo, opõe, claramente, o símbolo lógico e o hermenêutico: o primeiro, não tem conteúdos, é simplesmente formal e pode referir-se a uma realidade abstrata; o segundo, pelo contrário, tem múltiplos conteúdos e é doação de sentidos.

Finalmente, a criteriologia propõe a distinção entre o símbolo e o mito. Como afirmámos, Ricoeur propõe, desde o início do seu processo metodológico, uma mítica que se relaciona com o estudo do problema do mal através de uma classe particular de mitos, a saber: os mitos do princípio e do 
fim do mal. Se é verdade que o mito enquanto narrativa é uma simbologia que se exprime pela linguagem e que, por isso, pode ser inserida na reflexão filosófica, também é verdade que há uma linguagem que é anterior aos próprios mitos: a linguagem da confissão. Os mitos são símbolos de segundo grau e a linguagem da confissão inscreve-se nos símbolos de primeiro grau. Antes das narrativas míticas, o ser humano manifesta, pela confissão, as suas experiências externas e internas. Estamos, então, no âmbito dos símbolos primários tal como são apresentados em La symbolique du mal. Quando Ricoeur distingue símbolo e mito, há que ter em conta que, por símbolo, entende, especialmente, os símbolos de primeiro grau que emergem na linguagem da confissão do mal, anterior, portanto, ao desenvolvimento mítico; por outro lado, o mito é concebido como uma espécie de símbolo, um símbolo secundário que deriva dos símbolos primários. Ricoeur afirma a este respeito:

Entenderei sempre por símbolo (...) as significações analógicas espontaneamente formadas e imediatamente doadoras de sentido; assim, por exemplo, a mancha é análoga à sujidade, o pecado análogo ao desvio, a culpabilidade análoga a um fardo; estes símbolos estão ao mesmo nível que, por exemplo, o sentido que tem a água como ameaça e como renovação no dilúvio e no baptismo (...). Neste sentido, o símbolo é mais radical que o mito. Considerarei o mito como uma espécie de símbolo, como um símbolo desenvolvido em forma de narrativa e articulado num tempo e num espaço que não podem coincidir com os da história e da geografia segundo o método crítico; por exemplo, o exílio é um símbolo primário da alienação humana, enquanto a história da expulsão de Adão e Eva do Paraíso é uma narrativa mítica de segundo grau que põe em jogo personagens, lugares, um tempo, episódios fabulosos. (RICOEUR, 1995, p. 180-181).

Os símbolos primários são a linguagem elementar por meio da qual o sujeito expressa a experiência do mal ou da culpabilidade. Distinguem-se dos símbolos secundários pela ausência de narrativa, de articulação interna, de personagens, de lugares e tempos fabulosos, características que definem globalmente os mitos. O mito é, pois, um símbolo de segundo grau e, por isso, pode inserir-se a mítica na simbólica, o que permite, mediante a hermenêutica dos símbolos, aproximar a mítica à reflexão filosófica.

Em síntese, pode dizer-se que o problema que antes se colocava, isto é, o de saber como conciliar o mito com o discurso filosófico, tem agora um esboço de solução no âmbito da metodologia. Ao entender, em primeiro lugar, os mitos como símbolos, inscreve-se a mítica na simbólica; 
e, por outro lado, ao entender o símbolo como uma estrutura de duplo sentido, susceptível de uma hermenêutica, a simbólica do mal aproxima os mitos do discurso filosófico.

Com efeito, os símbolos ocultam uma dupla intencionalidade: em primeiro lugar, há uma intencionalidade literal, aparente que supõe o triunfo do signo convencional sobre o signo natural, como é o caso da mancha, desvio, opressão, etc. Estes signos não se identificam diretamente com a coisa significada: pelo contrário, sobre esta intencionalidade primeira edifica-se outra intencionalidade que aponta para uma certa experiência humana perante o sagrado. A situação descrita é, precisamente, a do ser manchado, pecador, culpado. Nesta perspectiva, a intencionalidade primeira ou primeiro sentido, oculta um segundo sentido, uma segunda intencionalidade, algo que está latente. Quando se fala da mancha, por exemplo, há algo oculto que afeta o ser humano na sua globalidade; a mancha é um símbolo do impuro em oposição ao símbolo da pureza. Consequentemente, Ricoeur começa a sua interpretação partindo de uma fenomenologia da confissão, uma vez que a linguagem da confissão pode revelar um significado exploratório.

\footnotetext{
Chamo aqui fenomenologia à descrição das significações implicadas na experiência em geral seja esta uma experiência das coisas, dos valores, ou das pessoas. Uma fenomenologia da confissão é pois a descrição das significações, e das intenções significadas, presentes numa certa actividade da linguagem: a confissão. A nossa tarefa, no quadro de tal fenomenologia, é a de repetir em nós mesmos a confissão do mal para, a partir dela, libertar as intenções. (RICOEUR, 1969, p. 416-417)
}

Como se disse, a linguagem da confissão expressa-se por símbolos. Todavia, há que distinguir os signos simbólicos dos signos técnicos: em oposição aos signos técnicos que se caracterizam pela transparência, na medida em que dizem o que querem dizer, os signos simbólicos caracterizam-se pela sua opacidade e profundidade, dado que o sentido literal aponta analogicamente para outro sentido que se situa para além do sentido literal ou patente. Cabe perguntar em que consiste a opacidade do símbolo. Ricoeur responde: «O símbolo permanece opaco, não transparente, uma vez que é dado por meio de uma analogia, sobre a base de um significado literal, que lhe confere, por sua vez, raízes concretas e um peso material, uma opacidade.» (RICOEUR; 1969, p. 313). 
O símbolo caracteriza-se, então, pela sua doação de sentido, ou seja, através do sentido primário é possível participar no sentido oculto; pela primeira intencionalidade pode-se participar na segunda. No entanto, esta doação introduz a contingência e a dependência no interior do próprio pensamento, na medida em que o símbolo é prisioneiro de uma certa diversidade cultural e linguística, o que implicará a introdução do conflito hermenêutico.

A investigação dos símbolos primários realizada por Ricoeur tem a vantagem de fazer emergir uma dinâmica simbólica que, na sua equivocidade, transporta a reflexão para uma dinâmica da experiência vivencial do ser humano, sobretudo no que diz respeito ao problema do mal.

Por outro lado, no próprio âmbito da simbólica pode entender-se o problema do mal como mistério. A relação com o insondável do mistério provoca no ser humano inquietude e angústia; inquietude que supõe um temor pelo enigmático e inescrutável e pela ignorância da origem. Todavia, o misterioso não fica totalmente resolvido através dos símbolos; estes podem ser apenas mediações que têm em vista o esclarecimento e a compreensão do mistério da vida nas suas origens; os símbolos podem, além disso, esclarecer o problema da origem do mal e a sua concretização na vida humana, mas o enigmático e misterioso da vida permanecem aporéticos. É neste ponto que a filosofia inicia a sua função: a de interpretar a linguagem simbólica para compreender os seus referentes.

Parece que estamos perante uma certa visão do mundo na qual o ser humano não pode ser apreendido a não ser a partir de uma certa aventura que o constitui como ser humano. De facto, esta aventura não pode ser realmente vivida sem a dimensão do mistério; o mistério de Deus, do mundo, da vida, do destino, do espaço e do tempo, do limite e do infinito, do princípio e do fim. O inescrutável mistério do mal é, definitivamente, um dos que maior inquietude e temor provocam no ser humano. Além disso, o mistério não tem que ser entendido como algo alheio e distante, mas está presente, de facto, na vida quotidiana, de modo que o ser humano nunca poderia iludi-lo completamente. O mistério é, sem dúvida, um enigma mas é, ao mesmo tempo, uma força que move a humanidade em direção à sua compreensão.

O problema do mal supõe uma ambiguidade de base: o mal só é mal porque o ser humano o introduz, o pratica; mas «no próprio coração da prática do mal pela liberdade revela-se um poder de sedução pelo mal 
anterior, pré-existente (déjà là) que a antiga mancha já havia manifestado de um modo simbólico.» (RICOEUR, 1988, p. 287). A simbólica revela-nos uma certa exterioridade do mal, algo que afeta o ser humano a partir do exterior. Mas, ao mesmo tempo, a dinâmica simbólica é animada por uma confrontação fundamental: por um lado, a origem do mal é o resultado de uma catástrofe ou de um conflito originário anterior ao ser humano que o mito nos revela; por outro, o mal tem a sua origem no interior do próprio ser humano. Os mitos trágicos, por exemplo, supõem já um destino fatal cuja alteração não está nas mãos do ser humano; mas, no mito adâmico, que é um mito fundamentalmente antropológico, é o ser humano quem, pela confissão do pecado, se descobre como o autor do mal. O mundo dos mitos está, pois, polarizado por duas tendências ou convicções: segundo uma delas, o mal é anterior ao ser humano, introduz-se do exterior (concepção trágica) e, segundo a outra, o mal é o resultado de uma escolha do homem (concepção ética), estando enraizado numa desproporção ontológica. Esta polaridade é já patente nos símbolos primários que constituem o primeiro nível de expressão da consciência culpada, como veremos de seguida.

Como dissemos, Ricoeur sustenta que há uma linguagem elementar que se encontra na base das primeiras narrativas míticas. Na base dos símbolos primários há uma experiência vivida do mal que se manifesta pela confissão. A mancha, o pecado e a culpabilidade são a expressão simbólica da experiência vivida do mal praticado; por intermédio de tais símbolos, é possível reproduzir a experiência concreta a um nível primário. Deste modo, a reflexão filosófica, antes de avançar para a especulação, terá de partir da experiência viva do ser humano e do respectivo sentido expresso pela linguagem.

Se o mal é anterior ao ser humano, se lhe pré-existe, como conciliar, então, a visão da anterioridade do mal com a visão da falibilidade humana como possibilidade do mal e com a consequente prática do mal por parte do ser humano?

Comecemos, pois, por dizer que a clarificação da questão colocada implica fazer um percurso pelo mundo dos símbolos míticos que tentam regressar à origem do mal. Os símbolos primários não comportam a dimensão narrativa; os símbolos míticos, pelo contrário, têm uma dimensão de relato e situam-se num plano temporal, desenvolvendo-se através da intervenção de personagens, lugares e tempos fabulosos; referem-se ao começo e ao possível fim de uma experiência que os símbolos primários 
testemunham. Nesta perspectiva, pode afirmar-se que, paradoxalmente, apesar de o mal poder ser anterior ao ser humano, sentimos que, de algum modo, começa connosco; é por isso que sentimos a necessidade de o exprimir, de o dizer por meio da confissão. Neste aspecto, a confissão do mal pode representar, do ponto de vista simbólico, uma possível via para tentar eliminá-lo, uma primeira tomada de consciência sem a qual nem sequer se poderia colocar o problema de ser ou não possível uma escatologia tendente a pôr-lhe fim. A confissão manifesta-se no interior de narrativas e discursos simbólicos nos quais emergem símbolos como os da mancha, do desvio, fardo, etc. e não tanto os de pecado ou de culpabilidade que são, em princípio, elaborações posteriores. A confissão aponta, pois, para a ideia de liberdade. Mas, ao mesmo tempo que a confissão do mal é o reconhecimento da liberdade e da responsabilidade, constitui também o reconhecimento dos limites de uma visão moral da liberdade humana, dado que a confissão implica a consciência do carácter injustificável do mal. Se, de facto, se pode dizer que o ser humano exerce o seu poder de livre-arbítrio ao escolher o mal, também se pode afirmar que a liberdade se volta contra si mesma, isto é, o livre-arbítrio converte-se num servo-arbítrio. No plano teórico-racional parece que estamos perante um problema de difícil solução. Daí que Ricoeur sustenha a necessidade de recorrer ao plano simbólico e à interpretação.

De facto, o nó de todo o problema hermenêutico está na articulação entre o discurso como acontecimento, a sua fixação no texto e os seus respectivos sentidos. Efetivamente, as significações do discurso representam a superação dos próprios acontecimentos experienciados, uma vez que estão dependentes de múltiplas interpretações.

\section{Hermenêutica do discurso: a pluridiversidade de sentidos}

A transição da hermenêutica dos símbolos para a hermenêutica do discurso não representa, na nossa perspectiva, uma ruptura no pensamento metodológico de Ricoeur, mas uma ampliação. De facto, o discurso é, também, simbólico - no sentido que Cassirer lhe atribui - e toda a experiência humana tem na sua base um carácter linguístico; e, enquanto tal, pode ser apreendida em termos simbólicos e metafóricos (estes últimos considerados, também, como formas linguísticas). Neste sentido, os diversos 
níveis da experiência humana manifestam-se e constituem uma semântica ${ }^{5}$ que só a hermenêutica filosófica pode compreender.

O projeto de Ricoeur de constituição de uma poética da vontade apresenta-se como uma segunda revolução coperniciana. O discurso é um acontecimento da linguagem. É o que se dá quando alguém, ao tomar a palavra, se dirige ao outro numa situação de interlocução e tem por finalidade expressar-lhe o sentido de algo.

Ao contrário do que acontece na linguística da língua, que tem por base o signo, a linguística do discurso edifica-se sobre a frase. É esta última que constitui a unidade de base do discurso e o suporte da dialética existente no discurso entre o acontecimento e o seu sentido. Esta dialéctica é o ponto de partida para a teoria do texto. (RICOEUR, 1986).

Como acontecimento, o discurso apresenta determinadas características: são os critérios da textualidade os que o constituem como discurso e nos permitem distingui-lo da língua, ao mesmo tempo que permitem distinguir a linguagem escrita da linguagem oral. Nesta perspectiva, o discurso realiza-se sempre no tempo presente e remete para um locutor através do uso de marcadores da subjetividade, como são os pronomes pessoais. Além disso, o discurso é intencional, isto é, refere-se a um mundo que pretende descrever ou significar implicando sempre, direta ou indiretamente, uma situação de interlocução, ou seja, a existência de outra pessoa com a qual se trocam mensagens. Ao mesmo tempo, o sistema da língua é algo virtual e estranho ao tempo; não requer a existência de um sujeito na sua concreção e os seus signos remetem apenas para outros signos no interior do mesmo sistema. Portanto, o sistema da língua é, acima de tudo, uma condição preliminar para que seja possível a comunicação, uma vez que subministra os códigos que a tornam possível.

Se todo o discurso é um acontecimento, tudo é compreendido como significação. (RICOEUR, 1986). Deste modo, Ricoeur introduz-nos na dialética existente entre o acontecimento da linguagem e o seu sentido. Não é já o acontecimento fugidio do discurso que se trata de compreender, mas o que dele permanece, isto é, o seu significado durável, o que é dito através dele. É na linguística do discurso e não no plano da língua que o acontecimento e a significação se articulam ultrapassando-se, deste modo, o acontecimento na

\footnotetext{
${ }^{5}$ Se Ricoeur fala de uma semântica do desejo na sua referência à psicanálise, será legítimo, do mesmo modo, em nossa opinião, falar de uma semântica da experiência. Assim, a gramática da vida envolve um semântica da experiência e da existência.
} 
significação. É, de facto, esta distanciação entre o dizer e o dito que constitui a base do problema hermenêutico. Mas a função hermenêutica da distanciação torna-se mais explícita e evidente na transição do discurso oral para o discurso escrito, isto é, quando o discurso se converte em texto. Neste âmbito, a interpretação, seja do texto escrito ou do 'texto' não escrito transforma-se em produção de sentido. (GISEL, 1970).

Como se disse, o acontecimento do discurso é de natureza temporal, realiza-se no presente e, por isso, aparece e desaparece. Daí que se coloque o problema da sua fixação - que pretende fazer do discurso algo atemporal - e, sobretudo, o do seu significado. O que se pretende fixar não é tanto o acontecimento que o discurso evoca, mas a sua significação.

A partir daqui, deixa de ser importante o autor do texto passando a sê-lo a interpretação. Partindo desta base, do ponto de vista hermenêutico, pode dizer-se que ler um livro é considerar o seu autor como já morto e a obra como póstuma. De facto, é quando o autor morre que se pode dizer que a sua relação com o livro se torna completa e, de algum modo, intacta. (RICOEUR, 1986).

Do mesmo modo, no texto escrito já não é possível saber qual foi a intenção do autor e os múltiplos significados do texto podem não coincidir com o que o autor quis dizer. O significado textual e o significado mental têm agora destinos diferentes. De facto, o que Gadamer chama «a coisa do texto» subtrai-se ao horizonte intencionalmente finito do seu autor; no entanto, por meio da escrita, o mundo do texto pode fazer explodir o mundo do autor. (RICOEUR, 1986). Nesta perspectiva, o texto representa uma abertura a mundos possíveis que o ser humano pode habitar ampliando-se, assim, o seu horizonte de sentido. Por outro lado, a fixação do discurso na escrita destrói a situação dialógica que caracteriza a oralidade e inaugura uma nova relação: o discurso passa a dirigir-se a todo o possível leitor. A distanciação que o próprio texto introduz é uma condição importante para que possa dar-se uma apropriação mais fecunda por parte dos possíveis leitores. Tendo em conta que também o texto é um conjunto de símbolos de múltiplos sentidos que fazem referência a realidades extralinguísticas, (RICOEUR, 1969) que apontam para diversos referentes, só pela hermenêutica e pela diversidade de hermenêuticas é possível a abertura do texto à realidade existencial. (RICOEUR, 1969, p. 67).

Definitivamente, pode dizer-se que a noção de acontecimento do discurso - que procede da prática efetiva da língua a qual, por sua vez, se 
concretiza na palavra -, ganha sentido a partir do momento em que é fixado pela escrita e, a partir daí, pode ser susceptível de múltiplas interpretações. A língua é ultrapassada pela palavra no discurso como acontecimento. No discurso, por sua vez, o acontecimento ultrapassa-se a si mesmo na significação; esta é superada pela sua fixação que é operada pela escrita. Finalmente, o próprio sentido do texto vai para além de si mesmo num novo acontecimento do discurso que é a sua própria interpretação. Deste ponto de vista, compreender um texto não é compreender a intenção do autor, mas produzir um novo acontecimento do discurso que já não se pode identificar com o acontecimento inicial.

O texto narrativo proporciona-nos uma história com autonomia própria. Essa história representa uma abertura a um mundo possível, na medida em que é um discurso fixado na escrita que se tornou, de algum modo, autónomo em relação ao seu autor e cuja mensagem se pode dirigir a um leitor qualquer, ao ser a sua referência situacional superada, sendo substituída por um mundo. A narrativa é um discurso que pode abrir-se a diversos seres humanos na sua respectiva experiência solitária no mundo.

Se a narrativa é esta complexa intriga na qual as ações, os personagens, o espaço e o tempo se ligam, desprendendo-se daí um sentido independente em relação à vontade de quem o enuncia, teremos que considerar cada texto como um mundo revelador de um mundo singular. Tal mundo é susceptível de múltiplas interpretações, inseridas nos correspondentes mundos dos leitores. No entanto, nem toda a interpretação pode ser considerada como necessariamente válida; de acordo com o princípio popperiano, implícito tanto na perspectiva de Umberto Eco como na de Ricoeur, algumas interpretações devem ser anuladas a partir de uma análise da estrutura do texto. Nesta perspectiva, sustenta-se a necessidade da existência de uma relação dialética entre a explicação e a compreensão, donde resulta uma interpretação do texto que não é, senão, uma conjectura defensável face a outras conjecturas. Ricoeur acrescenta a este respeito:

Para o hermeneuta, é o texto que possui um múltiplo sentido; (...). Ora, este problema do múltiplo sentido não é já hoje só o problema da exegese, no sentido bíblico ou inclusivamente profano da palavra; é em si mesmo um problema interdisciplinar que eu quero em primeiro lugar considerar num único nível estratégico, num plano homogéneo, o do texto. (...) $\mathrm{Na}$ 
hermenêutica não há clausura do universo dos signos. (RICOEUR, 1969, p. 66-67).

O que possibilita as diversas interpretações e o confronto entre elas é, efetivamente, a abertura da linguagem a múltiplos sentidos e o facto de o texto ser também uma abertura a uma diversidade de sentidos; é a riqueza do texto que nos conduz para além dos limites de referência aos quais a situação faz apelo. A linguagem é abertura ao mundo e não só a situações concretas. Neste sentido, o mundo do ser humano é constituído por todas as referências abertas pelos textos, sejam estes poéticos, míticos ou de outra índole.

Apesar de Ricoeur considerar que as narrativas míticas devem ser interpretadas respeitando o seu simbolismo originário, a verdade é que, segundo a teoria do texto do próprio Ricoeur, a pluralidade de sentidos que estas narrativas possibilitam representa uma maior amplitude para a compreensão do ser humano no mundo. Como afirma Manuel Maceiras, na «apresentação da edição castelhana» de Temps et récit:

Os mitos já não têm uma estreita relação com as classificações naturais e
sociais; a sua reinterpretação é possível em lugares e tempos muito
distintos, adquirindo significado na história que nestes se realiza: a sua
compreensão requer uma nova abordagem intelectual, que é a
compreensão hermenêutica. Neste trabalho articulam-se as três
historicidades: dos acontecimentos fundantes ou tempo oculto, da
interpretação que vive pelos escritores sagrados, que constitui a tradição,
e a historicidade da compreensão, a historicidade hermenêutica. A
significação é dada pela sequência completa ligada ao tempo e ao
intérprete tal como ao autor. (MACEIRAS, 1987, p. 24-25)

Com efeito, os acontecimentos, ainda que primordiais, só ganham sentido se puderem ser integrados na história existencial da humanidade e, em última instância, na sua experiência concreta. O tempo de que nos falam as narrativas míticas, tempo atemporal, pode, pela interpretação, ser transposto para um tempo histórico. Tempo histórico e tempo mítico, podem, por meio da hermenêutica, entrecruzar-se num tempo do sentido.(OMITIDO, 2009). É nesta confluência temporal que pode emergir o sentido da própria existência humana. 


\section{Considerações Finais}

É pela linguagem que o ser humano expressa os seus pensamentos, os seus desejos, os seus medos. A humanidade é linguagem. O símbolo e as narrativas míticas, também elas simbólicas, depois de interpretados, são meios pelos quais se pode compreender a condição humana, os seus limites e possibilidades existenciais. Os símbolos são verdadeiras provocações ao pensamento porque os sentidos simbólicos são inesgotáveis. É necessário inseri-los em narrativas para que possam, de algum modo, ser apropriados pela reflexão filosófica. O símbolo dá que pensar, expressão utilizada por Ricoeur em La Symbolique du mal. Todavia, não se trata, na última fase do pensamento hermenêutico do autor de descobrir a estrutura comum a todos os símbolos, mas tomar o símbolo como uma expressão de duplo sentido, susceptível de múltiplas interpretações. Se o símbolo é uma provocação ao pensamento, o mistério nele implícito constitui um "alimento" e estímulo para a filosofia e para a própria vida. A abertura da linguagem a múltiplos sentidos e o facto de o texto ser também uma abertura a uma diversidade de sentidos é o que possibilita as diversas interpretações e o conflito entre elas.

A questão da verdade não é o resultado de uma interpretação, mas do conflito entre elas. Daí a importância atribuída por Ricoeur a uma hermenêutica da suspeita que tem como referência os grandes autores que, de algum modo, estabeleceram rupturas com a tradição e com o monolitismo interpretativo e nos ensinaram que, efetivamente, a verdadeira realidade se encontra oculta e que, por isso, carece de interpretação: Marx, Nietzsche e Freud. É a riqueza do texto que nos conduz para além dos limites de referência aos quais a situação faz apelo. A linguagem é abertura ao mundo e não só a situações concretas. Neste sentido, o mundo do ser humano é constituído por todas as referências abertas pelos textos, sejam estes poéticos, míticos ou de outra índole. A ontologia proposta por Ricoeur, ontologia quebrada, ganha maior densidade por intermédio do percurso transitório entre a hermenêutica simbólica e a hermenêutica do discurso restauradora do sentido. 


\section{Referências}

GISEL, P. Le conflit des interprétations, Esprit, 38, nº 11, Novembre, 1970.

MACEIRAS, Manuel. Presentación de la edición española, Tiempo y narración I. Madrid: Ediciones Cristianidad, 1987, pp. 24-25.

PRIETO, Roxana. (1980) El problema del mal en la obra de Paul Ricoeur., Filosofia Oggi, 3, $\mathrm{n}^{\mathrm{o}} 1,1980, \mathrm{p} .394$.

RICOEUR, Paul. Le problème du double-sens. In Le Conflit des Interprétations. Essais d'herméneutique I. Paris : Éditions du Seuil, 1969.

RICOEUR, Paul. Temps et Récit, I. Paris : Éditions du Seuil, 1991.

RICOEUR, Paul. De l'interprétation. Essai sur Freud. Paris : Éditions du Seuil, 1995.

RICOEUR, Paul. Du texte à l'action. Essai d'herméneutique II. Paris : Éditions du Seuil, 1986.

RICOEUR, Paul. Philosophie de la volonté II. Finitude et Culpabilité I, L'Homme Faillible. Paris : Aubier Montaigne, 196o, 1988.

RICOEUR, Paul. Ricoeur, Respuesta a Tomás Calvo. In MARTINEZ, T. C. REMEDIOS, A. C. (Eds). Paul Ricoeur: los caminos de la interpretación. Barcelona: Anthropos, 1991.

OMITIDO. Tempo histórico e tempo mítico : a descoberta da identidade no «tempo do sentido». Revista Percursos, v. 10, nº 2, 2009, p. 55-76.

OMITIDO. The educational phenomenon between ideology and utopia. Paul Ricoeur's thought: foundations for an emancipatory education. Educação e Filosofia, v. 30, n. 6o, jul-dez. 2016, p. 739-773.

\section{Endereço postal:}

Programa de Pós-Graduação em Educação (PPGE) da UNINOVE

Avenida Vergueiro, $12^{\circ}$ São Paulo- SP, Brasil

Data de recebimento: o8/03/2018

Data de aceite: 17/09/2018 